\title{
Aerobic Bacteriology of Surgical Site Infections with Special Reference to Detection of Methicillin Resistant Staphylococcus aureus
}

\author{
R. Bindu Madhavi ${ }^{{ }^{*}}$ and A. R. Hanumanthappa ${ }^{2}$ \\ ${ }^{1}$ Department of Microbiology, Sri Devaraj URS Medical College, Affiliated to SDUAHER, \\ Kolar, Karnataka, India \\ ${ }^{2}$ Department of Microbiology, JJM Medical College, Davanagere, Karnataka, India \\ *Corresponding author
}

\section{A B S T R A C T}

\section{Keywords}

Surgical site infection, Hospital acquired infection, Staphylococcus aureus, MRSA

\section{Article Info}

\section{Accepted:}

20 December 2020

Available Online:

10 January 2021
Surgical site infections (SSI) continue to be a major problem among the hospital acquired infections. Among the pathogens Staphylococcus aureus (S. aureus) is known to cause SSI since many decades. SSI caused by Methicillin resistant Staphylococcus aureus (MRSA) has become an obstacle in the clinical outcome of patients undergoing surgery. SSI not only affects the patient's outcome but also increases the burden to the hospital, hence the present study was conducted to know the prevalence of MRSA causing surgical site infection and to know the antibiotic susceptibility pattern of the $S$. aureus causing surgical site infection. This study was conducted during June 2015 to May 2016, during which 140 samples were collected of whichE. coli (32.6\%) was the most common pathogen causing SSI followed by S. aureus (18.1\%). Prevalence of MRSA causing SSI is $13.6 \%$. Most of the isolates were resistant to commonly used antibiotics and choice of antibiotics for treatment were Amoxicillin-clavulanate, Imipenem, Meropenem and Linezolid. MRSA causing SSI continues to be a major challenge for treating surgeons, hence regular screening of health care workers to identify MRSA carriers, strict adherence to preventive measures during preoperative, operative and postoperative period and meticulous infection prevention control practices are the needed to bring down the SSI rates.

\section{Introduction}

Surgical site infection (SSI) is one among the most common hospital acquired infection, accounting for approximately a quarter of all hospital acquired infections. ${ }^{1}$ They are responsible for increasing the hospital cost, duration of hospital stay, mortality and morbidity related to surgeries. They not only increase the burden for the patients undergoing surgery, but also increase the burden on the treating surgeon. SSI continue to be a major problem even in hospitals with modern facilities and standard infection control measures. ${ }^{2}$ Most common pathogens causing SSIs are Staphylococci, Streptococci, Enterococci, E. coli, Klebsiella, Enterobacter, Citrobacter, Acinetobacter and Proteus.

$S$. aureus can be present as normal flora and can be isolated from anterior nares, axilla and perineum of healthy individuals, it can be 
isolated from noses of up to $60 \%$ of the healthy individuals and can be transmitted from one individual to others through hands and contaminated objects. Thus, if infection control practices are poor it can be easily transmitted among the healthcare workers and patients attending hospital. S.aureus continues to be one of the most common organism causing SSI. ${ }^{3,4}$ The incidence of hospital acquired infections due to MRSA continues to increase with incidence rate in India ranging from $30 \%$ to $70 \%{ }^{5,6}$ The present study was done to know the prevalence of MRSA causing SSIs and its antibiotic susceptibility pattern in our hospital, which helps to know the prevalence of MRSA causing SSI and also helps in choosing appropriate antibiotics.

The main objectives of this study include to know the prevalence of MRSA causing surgical site infection. And also to know the antibiotic susceptibility pattern of the $S$. aureus causing surgical site infection.

\section{Materials and Methods}

Study setup - The present study was conducted at department of Microbiology, JJM Medical College, Davangere.

Study period and design - The present study is a prospective cross-sectional study which was done during June 2015 to May 2016.

Sample size - Sample size was calculated by Cogent QC system using the prevalence rate of surgical site infections and it was estimated as 140 .

Ethical clearance - Ethical clearance was taken prior the start of the study from the institutional ethical committee.

Sample collection, processing, and identification

Patients who have undergone surgery were considered to have SSI according to the criteria set by Centre for Disease Control guidelines (CDC). ${ }^{7}$ Suspected patients with SSI who gave informed consent were included in the study; pus samples were collected from them and subjected to Grams staining, culture and sensitivity. Identification of the isolates were done using Grams stain and standard biochemical reactions., 8 Antibiotic susceptibility testing of the isolates was done using Kirby Bauer disc diffusion test on Muller Hinton agar using the following discs- Penicillin (10units), Erythromycin $(15 \mu \mathrm{g})$, Ciprofloxacin $(5 \mu \mathrm{g})$, Cotrimoxazole $(25 \mu \mathrm{g})$, Gentamycin $(10 \mu \mathrm{g})$, Linezolid $(30 \mu \mathrm{g}), \quad$ Amoxicillin $(20 \mu \mathrm{g})$, Imipenem $(10 \mu \mathrm{g}), \quad$ Cefotaxime $(30 \mu \mathrm{g})$, Cefoxitin $(30 \mu \mathrm{g})$ and interpretation was done according to CLSI guidelines. ${ }^{10}$

\section{Detection of $\mathrm{MRSA}^{10}$}

Detection of MRSA was done using Cefoxitin disc diffusion test. A $0.5 \mathrm{McFarland}$ standard suspension of the test organism was lawn cultured on Muller Hinton agar plate after which Cefoxitin disc $(30 \mu \mathrm{g})$ was placed and incubated at $37^{\circ} \mathrm{C}$ for 18 to 24 hours. Zone of inhibition measuring $\leq 21 \mathrm{mmwerereported} \mathrm{as}$ MRSA and those isolates with $\geq 22 \mathrm{~mm}$ were reported as MSSA.

\section{Results and Discussion}

In the present study, pus samples from SSI were collected from 140 patients, out of which suspected to have SSI. 78 (54.4\%) were male patients and $62(45.6 \%)$ were female patients.Age of the patients in the study ranged from 9 years to 70 years. Out of 140 samples, 125 samples yielded growth and 15 samples yielded no growth. Out of125 samples which yielded growth,13 samples showed polymicrobial growth and 112 samples showed monomicrobial growth, hence a total of 138 isolates were obtained. 
The most common pathogen isolated was E.coli $(32.6 \%)$ followed by S.aureus (18.1\%), Klebsiella spp (9.4\%), Pseudomonas aeruginosa (7.2\%), Proteus (4.3\%) and Citrobacter (2.9\%). Out of 140 samples, 37 samples $(26.4 \%)$ were from clean wounds, $28(20 \%)$ from clean contaminated wounds, $61(43.6 \%)$ from contaminated wounds and $14(10 \%)$ from dirty wounds as shown in table 1.72 samples $(51.4 \%)$ samples were collected from wounds over the abdominal wall, 40 samples (28.6\%) samples were collected from wounds over limbs and few other samples were from wounds over the other areas such as chest, head and neck regions and the ward wise distribution of samples is shown in figure 1.A total of 25 isolates of S.aureus were obtained out of which, 8 isolates were MRSA whereas 17 isolates (68\%) were identified as MSSA as shown in figure 2. Prevalence of MRSA causing surgical site infection in the present study is $13.6 \%$. All S.aureus isolates in our study were sensitive to Linezolid and resistant pattern to other antibiotics is shown in figure 3.

Table.1 Surgical site infection and type of wound

\begin{tabular}{|l|c|c|}
\hline Type of wound & $\begin{array}{c}\text { No. of samples } \\
\text { collected }\end{array}$ & $\begin{array}{c}\text { No. of culture positive } \\
\text { samples }\end{array}$ \\
\hline Clean & 37 & $30(81 \%)$ \\
\hline $\begin{array}{l}\text { Clean } \\
\text { contaminated }\end{array}$ & 28 & $22(78.6 \%)$ \\
\hline Contaminated & 61 & $60(98.4 \%)$ \\
\hline Dirty & 14 & $13(92.8 \%)$ \\
\hline Total & 140 & $125(89.3 \%)$ \\
\hline
\end{tabular}
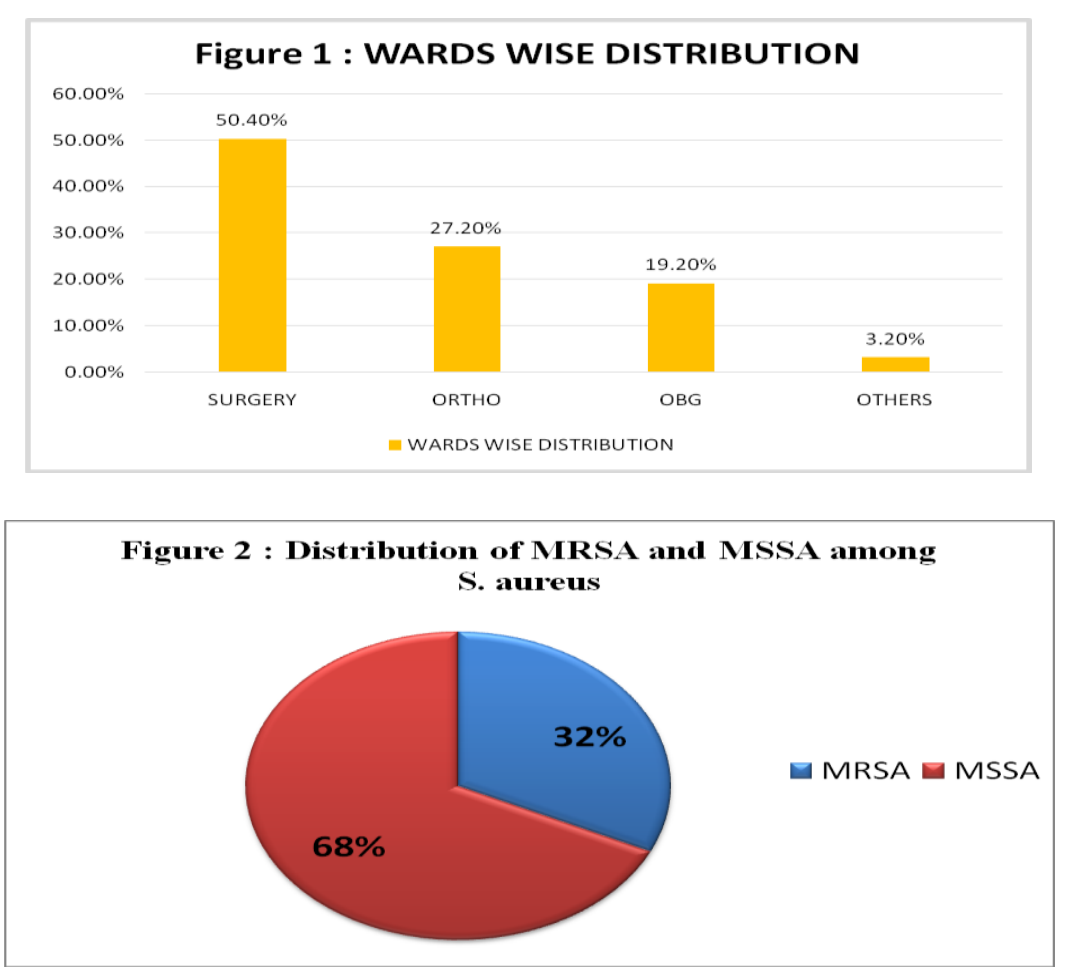


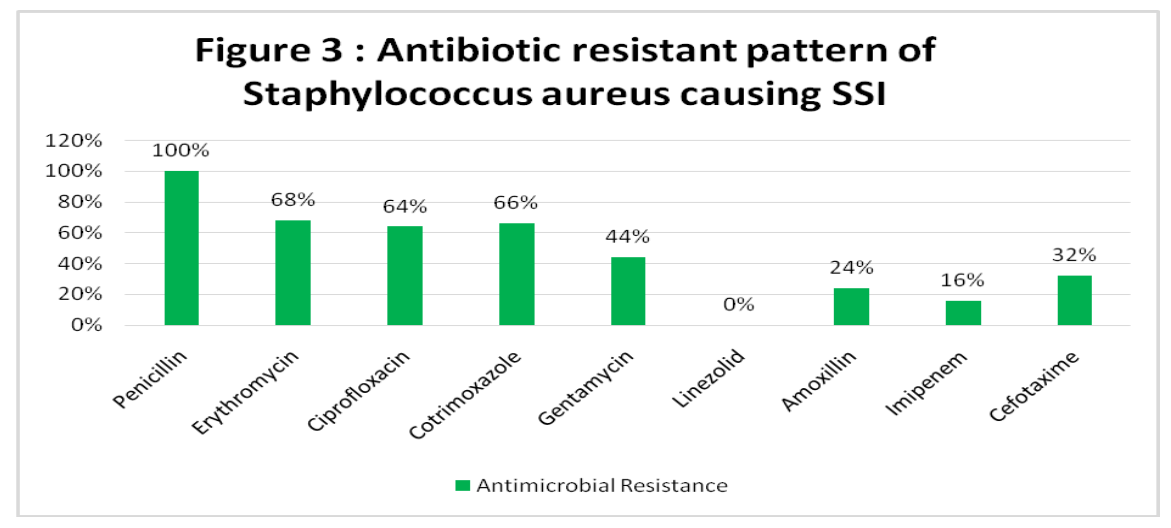

Fig.4 Detection of MSSA AND MRSA using Cefoxitin disc diffusion test

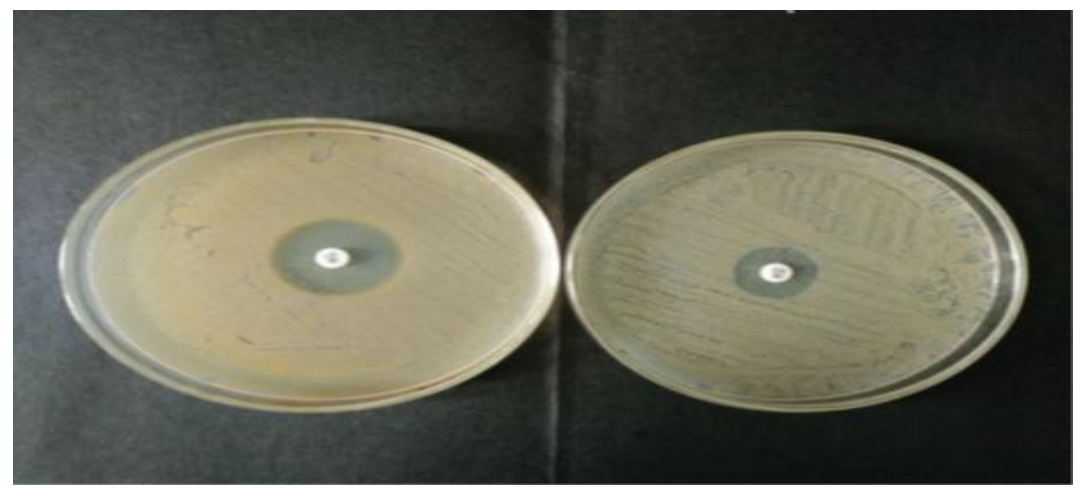

Based on the site of sample collection SSI was more common from wounds over abdominal wall followed by wounds over the limbs. This explains the increased prevalence of gram negative bacilli causing SSI, as major number of the surgeries in our study involved gastrointestinal tract.SSI were more common in contaminated and dirty wounds, which is self-explanatory as the type of the wound will explain the bacterial load at the surgical site. Similar findings was also found in other studies done by Wanjare, et al ${ }^{11}$ and Rambabu et $a l^{12}$. In our study diabetes and malignancy were some of the pre-existing illness found in patients having SSI, other pre-existing illness include obesity, immune disorders, prolonged antibiotic use, anaemia, hypertension etc. ${ }^{13,14,15}$ The most common pathogen causing SSI in our study is E.coli $(32.6 \%)$ followed by S.aureus (18.1\%). S.aureus continues to be one among the most common pathogen causing SSI, Rambabu et $a l^{12}$ and Satyam G et al ${ }^{16}$ also reported $S$. aureus as the most common pathogen causing SSI. Most effective antibiotics against S.aureus were Linezolid, Imipenem, Meropenem and Amoxicillin-clavulanate, whereas all the S.aureus isolates were resistant to Penicillin, $68 \%$ of them were resistant Erythromycin and $66 \%$ were resistant to Cotrimoxazole. Almost similar results were found in studies done by Krishna et $a l^{19}$, Negi $\mathrm{V}$ et $a l^{20}$ and Ranjan, ${ }^{17}$ et al. Prevalence of MRSA causing SSI in our study is $13.6 \%$, whereas in other studies done by Ranjan et $a l^{17}$, Wanjare V S et $a l^{11}$ and Sultan A et $a l^{18}$ were found to be $27.9 \%$, $37.14 \%$ and $39.6 \%$ respectively. In a study done by Bhattacharya $\mathrm{S}^{21}$ et al, SSI were predominantly caused by $S$. aureus $(34.93 \%)$, prevalence of MRSA was $25.45 \%$ and all the MRSA isolates were sensitive to Linezolid, other highly sensitive drugs were Levofloxacin and Doxycycline. In a study done by Rao, et $a l^{8}$ prevalence of MRSA causing SSI was as high as $66.4 \%$. In the present study no isolates were found to be 
resistant to Linezolid and Vancomycin; other higher antibiotics like Tigecycline, Daptomycin, Quinupristin-Dalfopristin were not tested in our study. Several other studies have showed that MRSA infections are life threatening and it is of great concern because of their resistance to commonly used antibiotics. ${ }^{4} S$. aureus continues to be the most common primary aetiological agent causing surgical site infections from past thirty years. It is well known fact that surgical site infection increases the duration of hospital stay, cost of treatment and affects the mortality and morbidity rates. ${ }^{22}$ Easy availability of antimicrobial agents, inappropriate use of antibiotics and poor infection control practices could increase the load of multidrug resistant organisms in the community. ${ }^{23,}{ }^{24}$ Though SSI could not be completely reduced, efforts should be made to bring down the SSI rates to minimum. Strict infection prevention control practices have to be adopted and followed during preoperative, operative and postoperative care. Misuse of antibiotics should be avoided which helps in preventing unnecessary exposure of patients to antibiotics.

In the present study prevalence of MRSA causing SSI is $13.6 \%$. Most of the $S$. aureus isolates are resistant to commonly used antibiotics, of which the choice of antibiotics for treatment were Amoxicillin-clavulanate, Imipenem, Meropenem and Linezolid. SSIs observed in the health care system setups are only the tip of the iceberg, regular surveillance of SSI with antibiotic susceptibility pattern of the isolates are needed to know the trend of SSI. Although SSI cannot be completely eliminated, efforts have to be made to reduce SSI, which helps in bringing down the mortality and morbidity.

\section{References}

1. Mangram AJ, Horan TC, Pearson ML, Silver LC, Jarvis WR. Guideline for prevention of surgical site infection. Infect control hospepidemiol 1999; 20:247-78.

2. Yalcin A N, Bakir M, BakiciZ, Dolmetas I, Sabir N. Postoperative wound infections.J hosp Infect 1995;29: 305-9.

3. Nichols RL. Current Strategies for Prevention of Surgical Site Infections: Curr Infect Dis Rep2004 Dec; 6(6):426-434.

4. Naik, G. \& Deshpande, S.R. A study on surgical site infections caused by staphylococcus aureus with a special search for methicillin-resistant isolates. Journal of Clinical and Diagnostic Research 2011; 5. 502-508.

5. Verma S, Joshi S, Chitnis V, Hemavani N, Chitnis D. Growing problems of Methicillin Resistant Staphylococci-Indian Scenario. Indian J Med Sci 2000; 54:535-40.

6. Bratzler DW, Hunt DR. The surgical infection prevention and surgical care improvement projects: national initiatives to improve outcomes for patients having surgery. Clin Infect Dis 2006; 43:322-330.

7. Infect Control Hosp Epidemiol.1999 Apr; 20(4):250-78.

8. Rao R, Sumathi S, Anuradha K, Venkatesh D, Krishna S. Bacteriology of postoperative wound infections. Int $\mathrm{J}$ Pharm Biomed Res 2013;4(2):72-76.

9. J. G. Collee, J.P.Duguid, A.G.Fraser, B.P. Marmion and A.Simmons. Mackie and McCartney Practical Medical Microbiology. 14th edition, Churchill Livingstone Elsevier, New Delhi; 2007.

10. Clinical and Laboratory Standards Institute. CLSI performance standards for antimicrobial susceptibility testing: 26th informational supplement. CLSI M 100523.Clinical and Laboratory Standards Institute, Wayne, PA. 2016

11. Wanjare VS, Wanjare SW, Rahule AS, Mahato LO, Balvir TK. A Study of Postoperative Wounds Infections with Special Reference to Staphylococcus Aureus - A Study in a Tertiary Care Centre of Vidarbha Region of India: $N$ J Cont Med A Dent Jan-Apr 2014 ; 2(1): 32-39.

12. Rambabu V, Rajasekhar K, Reddy N D K, Kumar G S. "Study on Surgical Site Infections Caused By ESBL Producing Gram Negative Bacteria". Journal of 
Evidence based Medicine and Healthcare. Sep 2015; 2(38): 6092-97.

13. Juan Francisco Casanova Herruzo R,Jesus Diez.Risk factors for surgical site infection in children. Infection Control and Hospital Epidemiology.July 2006;27(7):709-715.

14. Nguyen D, MacLeod W. B, Phung DC,Cong QT, Nguyan VH,Harmer DH. Incidence and predicators of surgical site infection in Vietnam. Infection Control Hospital Epidemiology 2001;22:485-92.

15. Bhatia JY, Pandey K, Rodrigues C, Mehta A, Joshi VR. Postoperative wound infection in patients undergoing coronary artery bypass graft surgery, A prospective study with evaluation of risk factors. Indian $\mathbf{J}$ of Med Microbiol.2003; 21: 246-251.

16. Satyam G, RaoS G. Postoperative Wound Infection in Surgical Ward. Journal of Medical Science and Clinical Research. July 2016; 4(7):11283-90.

17. Ranjan K P, Ranjan N, Gandhi S. Surgical site infections with special reference to Methicillin Resistant Staphylococcus aureus: experience from a tertiary care referral hospital in North India. International Journal of Research in Medical Sciences. 2013; 1(2):108-11.

18. Sultan A, Rizvi M, Khan F, Ali S, Shukla I, Khatoon A. Incidence of surgical site infections, their etiology, associated antimicrobial use and antimicrobial resistance in a tertiary care centre in northern India. North American Journal of Medical Sciences. 2015 Nov; 2(7): 347-352.

19. Krishna S, Divya P, Shafiyabi S. Postoperative surgical wound infections with special reference to methicillin resistant Staphylococcus aureus: an experience from VIMS hospital, Ballari. J Biosci Tech. 2015; 6(3):697-702.

20. Negi V, Pal S, Juyal D, Sharma MK, Sharma N. Bacteriological profile of surgical site infections and their antibiogram: a study from resource constrained rural setting of Uttarakhand state, India. J Clin Diagn Res. 2015; 9(10):17-20.

21. Bhattacharya S, Pal K, Jain S, Chatterjee S S, Konar J. Surgical site infection by methicillin resistant staphylococcus aureuson decline?. Journal of Clinical and Diagnostic Research. September 2016;10(9): 32-36.

22. Edwards LD: The Epidemiology of 2056 Remote Site Infections and 1966 Surgical Wound Infections occurring in 1865 patients: Annals of Surg: 1976; 184; 758-66.

23. Lilani S. P, Janagale, N, Chowdhary A, Daver G. B. Surgical site infection in clean and contaminated cases. Indian $\mathbf{J}$ of MedMicrobiol2005; 23:249-52.

24. Keith SK, Deverick JA, Sloane R, Chen LF, Choi Y, Link K, Sexton DJ, Schmader KE: The impact of Surgical Site Infection on older operative patients: J AmGeriatr Soc. 2009 January; 57(1):46-54.

\section{How to cite this article:}

Bindu Madhavi, R. and Hanumanthappa, A. R. 2021. Aerobic Bacteriology of Surgical Site Infections with Special Reference to Detection of Methicillin Resistant Staphylococcus aureus. Int.J.Curr.Microbiol.App.Sci. 10(01): 3311-3316. doi: https://doi.org/10.20546/ijcmas.2021.1001.387 